\title{
Concept of modern optical training labs for optical engineering students
}

\section{Sergey Stafeev, Yuri Kolesnikov, Alexander Smirmov}

Sergey C. Stafeev, Yuri L. Kolesnikov, Alexander V. Smirmov, "Concept of modern optical training labs for optical engineering students," Proc. SPIE 2525, 1995 International Conference on Education in Optics, (13 October 1995); doi: 10.1117/12.224024

Event: SPIE's 1995 International Symposium on Optical Science, Engineering, and Instrumentation, 1995, San Diego, CA, United States 


\title{
Concept of Modern Optical Training Labs for Optical Engineering Students
}

\author{
Serguej C. Stafeev; Yuri L. Kolesnikov, Alexander V. Sminnor
}

General Physics Department of St.Petersburg Institute of Fine Mechanics \& Optics (PIFMO)
1+ Sablinskaya st., St. Petersburg, 197101 Russia

\begin{abstract}
This contribution is the extension of our communications on conferences EDUCATION IN OPTICS in RUSSIA 1991 \& HUNGARY 1993 [1-3]. The aim of this report is to present general principles and detailed program of training labs in Geometrical, Wave and Quantum optics on the General Physics level (for second year students). In recent years this concept has been employed in St.Petersburg Institute of Fine Mechanics \& Optics.
\end{abstract}

\section{INTRODUCTION}

The statements of this report are dedicated to organization of process, software and hardware for laboratory. course in Optics in the course of general Physics for students of Universities and Polytechnical Institutes in Russia, who are specialized in Optics, optical Mechanics and Electronics. The total amount of training hours is from 18 ( 9 two-hours classes) to 48 ( 12 four-hours classes) in one term. The main advantages of proposed Teaching Technique are the module construction, high flexibility, good consolidation of the lecture material and wide range of optical test-objects. It allows students to study not only traditional phenomena, but also the modern applications of wave and quantum optics. The examples of students curriculum and labs are also discussed.

\section{GENERAL PRINCIPLES}

Rapid development of optical technologies demands the change of the conception of study Optics. We consider the students, who study General Physics, now have to understand the main modern optical phenomena and can operate new equipment such as diffraction, gradient and holographic elements, laser technics, nonlinear effects, biomedical and ecology application, optical computers and information systems, image processing etc. In the teaching laboratory or lecture courses all those mean:

- connection between traditional parts (interference, diffraction, polarization etc.) and modern optical phenomena in the same period of time;

- teaching the classic optical phenomena by using modern objects of study - film and photolitographic structures, semiconductor materials, fiber-optics or liquid-crystal elements; - using the examples of digital image analysis, CCD - devices and computer simulation.

The deep teaching of modern Physics usually demands the deep knowledge of Mathematics. At the same time, the study of the theoretical material beside real physical phenomena is not effective. That is why, Purposes of deep laboratory course in Optics are illustration and good motivation of application of matrix in geometry optics and polarization, correlation analysis in study coherence, elements of Fourier transform in diffraction, spatial filters etc.

It is important to inoculate in students the skills to make experiments by using laser and diode sources of light, systems of forming spectral and spatial properties, fiber optical systems, various receivers of radiation. The equipment has to make possible the realization of various interference schemes, phase methods, demonstration of properties of diffraction and holographic elements.

\section{MODULAR EQUIPMENT}

The laboratory course should make possible the realization not less then 3-4 labs per one tutorial, and each lab should be supported by the number of objects. Variance of the methods and objects allows to change the study. program, depending on level of students and their specialization. We consider, the provision of variance can be made by module principle of the laboratory equipment. An optical module educational laboratory (OMEL) enable to provide the studies by frontal manner in accordance with the lecture matter (see Table.1). The OMEL covers main sections of the course, namely: laws of geometrical optics, photometry, interference of coherent and partial coherent light sources, simple apertures diffraction (see Table 2, A - general level, B - deep level, C - high level), diffraction on the regular and irregular structures, polarization, dispersion, reflection and absoption of light, atomic and molecular spectra, solid emission spectra. The OMEL equipment is formed br refered module principle [2]. With the aid of module equipment (optical constructor) the students may realize various optical sets in different versions (from usual "manual" to automatized installations under IBM PC control). The modification of optical sets needs a minimum time. 
Table 1. Contens of the lecture course "Wave \& Quantum Optics" with topics of module labs.

\begin{tabular}{|c|c|c|c|}
\hline 1 & 2 & 3 & 4 \\
\hline & Minimum course & Enhanced course & Labs $(3 \ldots+h)$ \\
\hline 1 & $\begin{array}{l}\text { Introduction. Optotechnics - key to modern } \\
\text { hight technology: }\end{array}$ & $\begin{array}{l}\text { Temporal \& Spartial Fourier } \\
\text { Transform: Properties. Examples. }\end{array}$ & \\
\hline 2 & $\begin{array}{l}\text { Electromagnetic nature of light. Plane \& } \\
\text { Spherical Waves, Wave Groups } \\
\text { Dispersion. Phase \& Group Velocity. }\end{array}$ & & $\begin{array}{l}\text { Acquaintance with } \\
\text { Hard- \& Soft Ware }\end{array}$ \\
\hline 3 & $\begin{array}{l}\text { Ray Optics. Principal Laws. Lenses \& } \\
\text { Mirrors. Optical Devices Classification. }\end{array}$ & $\begin{array}{l}\text { Gradient Mediums. Normal Modes. } \\
\text { Principals of Fiber Optics. }\end{array}$ & \\
\hline 4 & $\begin{array}{l}\text { Energy of Light. Photometry. Real Light } \\
\text { Sourses. Padiation Spectrum. Broadening. }\end{array}$ & & $\begin{array}{l}\text { Ray Optics \& } \\
\text { Photometry. }\end{array}$ \\
\hline 5 & $\begin{array}{l}\text { Interference of monochromatic \& } \\
\text { nonmonochromatic Waves. Coherence of } \\
\text { Light. Coherence Time \& Length. }\end{array}$ & $\begin{array}{l}\text { Coherence \& Correlation. Complex } \\
\text { Degree of Coherence. Convolution. } \\
\text { Autocorrelation. }\end{array}$ & \\
\hline 6 & $\begin{array}{l}\text { Young's Double Slit. Fresnel's Biprism. } \\
\text { Lloyd's Mirror. Stellar Interferometer. } \\
\text { Source Size \& Coherence }\end{array}$ & & Interference I. \\
\hline 7 & $\begin{array}{l}\text { Division of Amplitude. Newton's Rings. } \\
\text { Thin Films. Equal Thickness Stripes. Twin- } \\
\text { Beam Interferometers Classification. }\end{array}$ & $\begin{array}{l}\text { Temporal Coherence. Contour of } \\
\text { Spectral Line. Fourier Transform } \\
\text { Spectroscopy. }\end{array}$ & \\
\hline 8 & $\begin{array}{l}\text { Multiple Beam Interference. Fabry-Perot } \\
\text { Interferometer. Resolution in Wavelength. } \\
\text { Interference Filters. }\end{array}$ & & Interference II. \\
\hline 9 & $\begin{array}{l}\text { Interference of secondary Waves. Huygens } \\
\text { Fresnel Principle. Half-Period Zones. } \\
\text { Phasor Diagram. Poisson's Spot. Zone } \\
\text { Plate. General Aperture. }\end{array}$ & $\begin{array}{lrr}\text { Kirchhoff's } & \text { Diffraction } & \text { Theory. } \\
\text { Diffraction \& Spatual Fourier } & \text { F Sperties of Zone Plates. }\end{array}$ & \\
\hline 10 & $\begin{array}{l}\text { Fresnel's \& Fraunhofer Diffraction. } \\
\text { Cornu's Spiral. Rayleigh Distance. Single } \\
\text { Slit. Rectangular \& Round Aperture. }\end{array}$ & & Diffraction I. \\
\hline 11 & $\begin{array}{l}\text { Diffraction Patterns of the } \mathrm{N} \text { Slits. } \\
\text { Diffraction Gratings. The Effect of Slit } \\
\text { Width \& Shape. X-Ray Diffraction. }\end{array}$ & $\begin{array}{l}\text { Diffraction at a Ring Aperture. Babinet } \\
\text { rinciple. Fourier Transforms in Grating } \\
\text { Theory. Fractal Diffraction. }\end{array}$ & \\
\hline 12 & $\begin{array}{l}\text { Diffraction Theory of Imagening. Abbe- } \\
\text { Porter Experiment. Resolving Power. } \\
\text { Rayleigh Criteria. Coherent Illumination. }\end{array}$ & & Diffraction II. \\
\hline 13 & $\begin{array}{l}\text { Sin-Gratings. Sound Waves Diffraction. } \\
\text { Holography. Holograms of Plane \& } \\
\text { Spherical Waves. Thick Holograms. }\end{array}$ & $\begin{array}{l}\text { Spatial Filtering. Basics of Fourier } \\
\text { Optics. Phase-Contrast Microscopy. } \\
\text { Computer Generated Holograms. }\end{array}$ & \\
\hline
\end{tabular}




\begin{tabular}{|c|c|c|c|}
\hline 1 & 2 & 3 & 4 \\
\hline 14 & $\begin{array}{l}\text { Isotropic Propagation. Refractive Index \& } \\
\text { Wave Impedance. Fresnel's Fomulas. } \\
\text { Lorentz Dispersion Theory. Absorption. }\end{array}$ & & $\begin{array}{l}\text { Dispersion \& } \\
\text { Absorption. }\end{array}$ \\
\hline 15 & $\begin{array}{l}\text { Polarization of Light. Elliptical. Circular \& } \\
\text { Plane Polarizations. Derices \& } \\
\text { Measurements. Natural \& Induced } \\
\text { Birefringence. Optical Activity. }\end{array}$ & $\begin{array}{l}\text { Formal Description. Stokes Parameters. } \\
\text { Poincare's Sphere. Coherence \& } \\
\text { Polarization. Basics of Crystal Optics. } \\
\text { Polarized Rays Interference. }\end{array}$ & \\
\hline 16 & $\begin{array}{l}\text { Elastic \& Nonelastic Scattering. Classical \& } \\
\text { Quantum Description. Thermal Radiation. } \\
\text { Photons. Plank's Formula. }\end{array}$ & & $\begin{array}{l}\text { Polarization \& } \\
\text { Scattering }\end{array}$ \\
\hline 17 & $\begin{array}{l}\text { Spontaneous \& Stimulated Emission. Light } \\
\text { Amplification. Classification of Lasers. } \\
\text { Basics of Nonlinear \& Fiber Optics. }\end{array}$ & $\begin{array}{l}\text { Optical Cavities. Modes. Gaussian } \\
\text { Beam Optics. Ultra Short Pulses. } \\
\text { Solitons. Optical Bistability. }\end{array}$ & \\
\hline 18 & $\begin{array}{l}\text { Photoeffect. Pressure of Light. Thomson \& } \\
\text { Compton Scattering. Necessity for } \\
\text { Quantum-Mechanical Approach. }\end{array}$ & & Lasers \& Fibers. \\
\hline
\end{tabular}

Table 2. Laboratory occupation N 4 - Diffraction I ( diffraction on the single objects )

\begin{tabular}{|c|c|c|}
\hline$\square$ & Expermental investigations & Results \\
\hline Al & $\begin{array}{l}\text { Measurements of Diffraction at a Single Slit with } \\
\text { different Widths }\end{array}$ & $\begin{array}{l}\text { Dependence on the Slits Width, Check-Up the } \\
\text { Condition of the Fraunhofer Diffraction }\end{array}$ \\
\hline A2 & $\begin{array}{l}\text { Measurements of Diffraction at a Circular Apertures } \\
\text { (Holes, Discus \& Rings) }\end{array}$ & $\begin{array}{l}\text { Calibration of the Ary's Spot, Size Determination, } \\
\text { Features of the Ring's Diffraction. }\end{array}$ \\
\hline A3 & $\begin{array}{l}\text { Study of the Fresnel Diffraction, Changing the } \\
\text { Quantity of Half-Period Zones. }\end{array}$ & $\begin{array}{l}\text { Check-Up the Rayleigh Criterion, Observation of } \\
\text { the Poisson Spot. }\end{array}$ \\
\hline $\mathrm{Bl}$ & $\begin{array}{l}\text { Study of the Resolution Limits, Coherent \& Non- } \\
\text { coherent Illumnation. }\end{array}$ & Determination of the Resolving Power. \\
\hline B2 & Testing the Amplitude \& Phase Zone Plates. & $\begin{array}{l}\text { Measurements of the Main \& Multiple Focus } \\
\text { Lenghts, Intensity Comparison. }\end{array}$ \\
\hline $\mathrm{Cl}$ & $\begin{array}{l}\text { Study of the Diffraction at the Phase Objects, Phase- } \\
\text { Contrast Microscopy. }\end{array}$ & $\begin{array}{l}\text { Determination of the Phase Shifts, Choice of the } \\
\text { Most Effective Procedure. }\end{array}$ \\
\hline $\mathrm{C} 2$ & $\begin{array}{l}\text { Spatial Filtering: Application of Different Binary } \\
\text { Masks . }\end{array}$ & $\begin{array}{l}\text { Observation of the Images, Calculation of the } \\
\text { Spatial Frequences. }\end{array}$ \\
\hline $\mathrm{C} 3$ & $\begin{array}{l}\text { Study of Gaussian Beam Diffraction and Diffraction } \\
\text { at a Apodise Aperture. }\end{array}$ & $\begin{array}{l}\text { Input Amplitude Distribution Dependence of the } \\
\text { Resolving Power. }\end{array}$ \\
\hline
\end{tabular}

The basic elements of OMEL are the modules (manual or controllable by PC) for fine turnings of optical elements, test-objects, photosensors etc. The View of the Optical Laboratory with Modular Equipment can be seen in Fig.1. This Equipment is supported by Windows Interactive Software (see Fig.2 and [4]). Modules were produced uniformly, have the same contact ware and so they can be composed in various combinations for realization of different measuriments schemes, which are shown in Fig.3. Modules in common use are: axes and vertical turning module, spectral selection module, photosensor pinehole or matrix module, shutter module. Exept this, there are auxiliary modules: sources of light (coherent and incoherent), photodetectors, support elements, screens etc. 


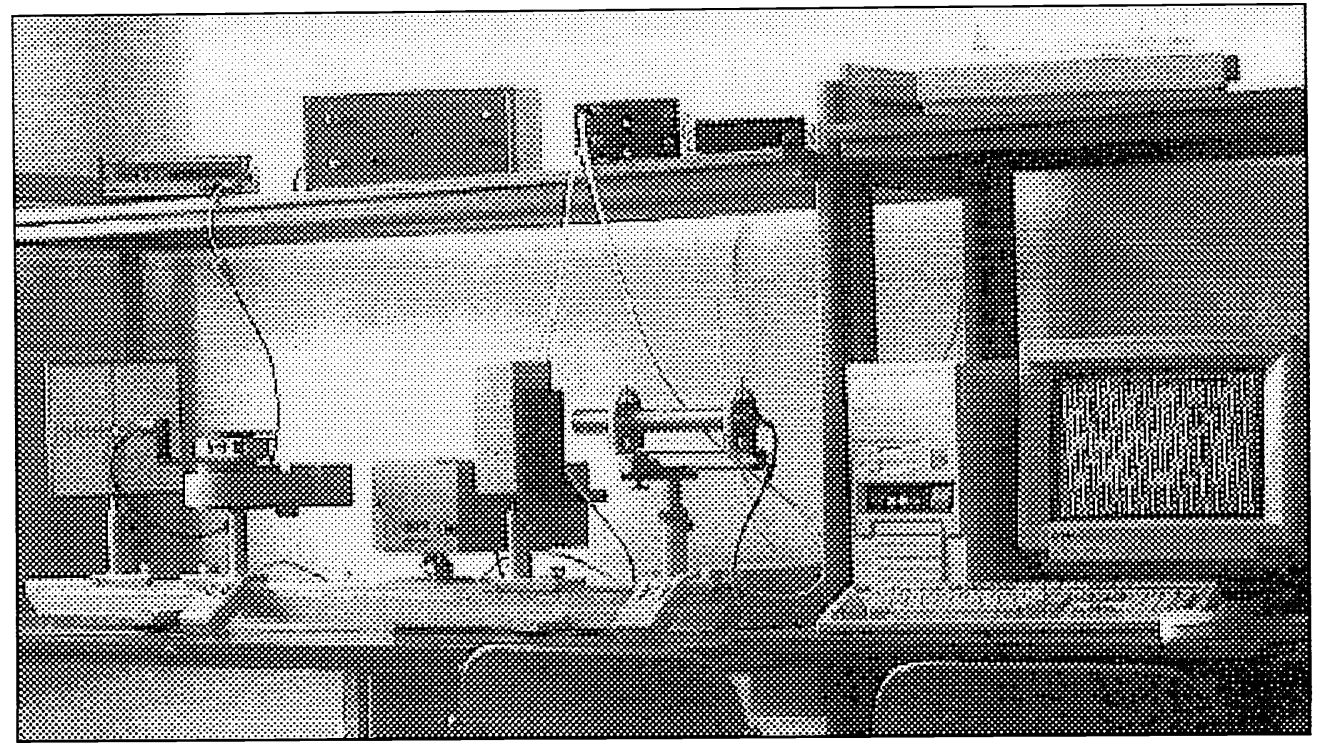

Fig. 1 View of the Optical Laboratory with Modular Equipment.

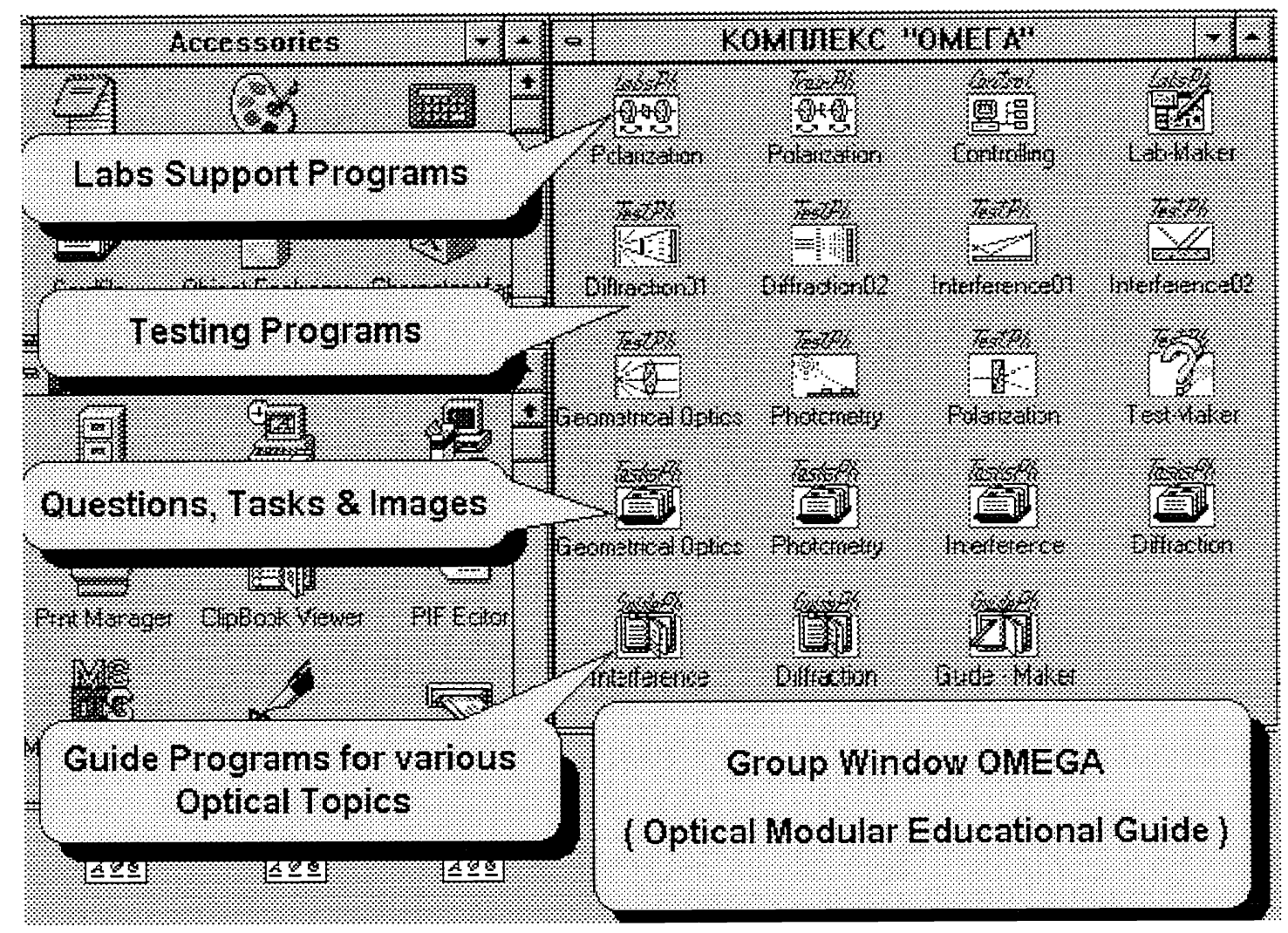

Fig.2 Group Window of Interactive Software for Enhanced Study of Optics. 
A.

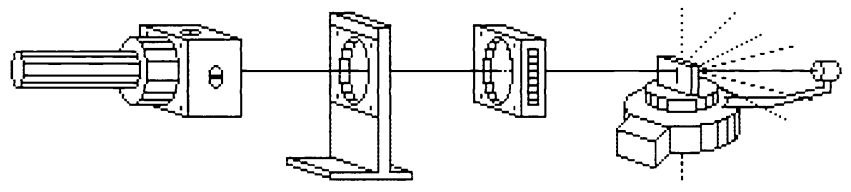

B.

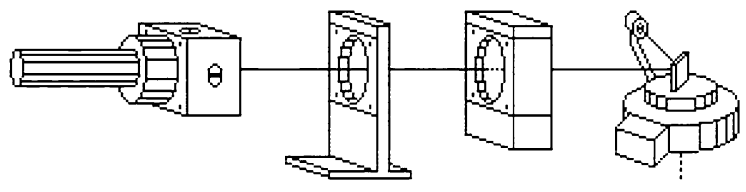

C.

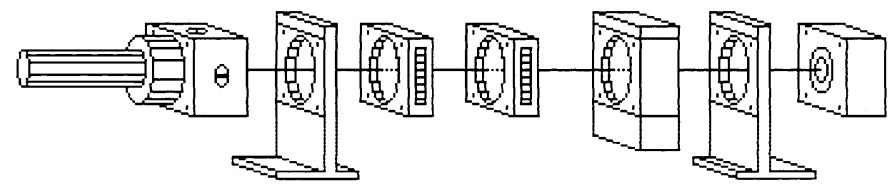

D.

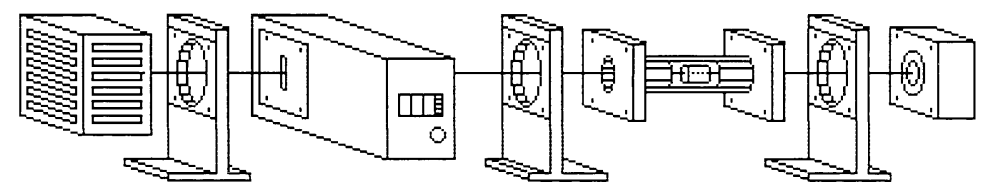

E.

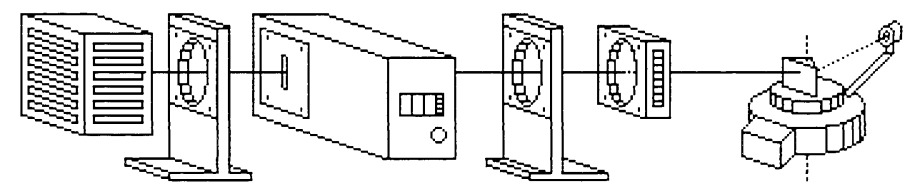

F.

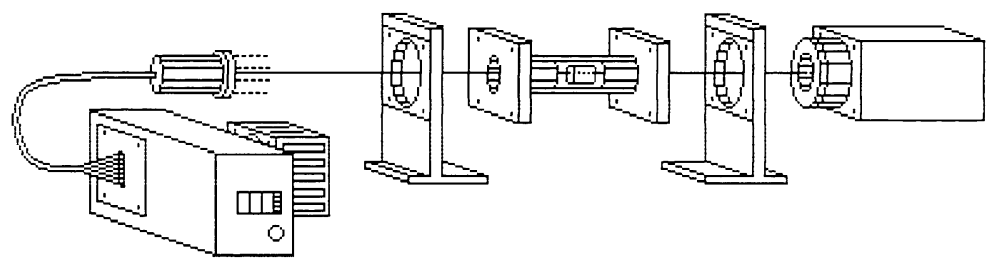

Fig.3 Examples of Modular Setup for Optical Traning Labs:

A - STUDY OF DIFFRACTION, INTERFERENCE \& DISPERSION OF LIGHT

B - STUDY OF REFLECTION FROM VOLUME MATERIALS \& FILM STRUCTURES

C - MEASUREMENTS OF POLARIZATION PARAMETERS

D - THE INVESTIGATION OF ABSORPTION, EMISSION \& FLUORESCENSE SPECTRA

E - THE DETERMINATION OF REFRACTIVE INDEX \& WAVE IMPEDANCE

F - THE STUDY OF INTERFERENCE \& POLARIZATION IMAGES 


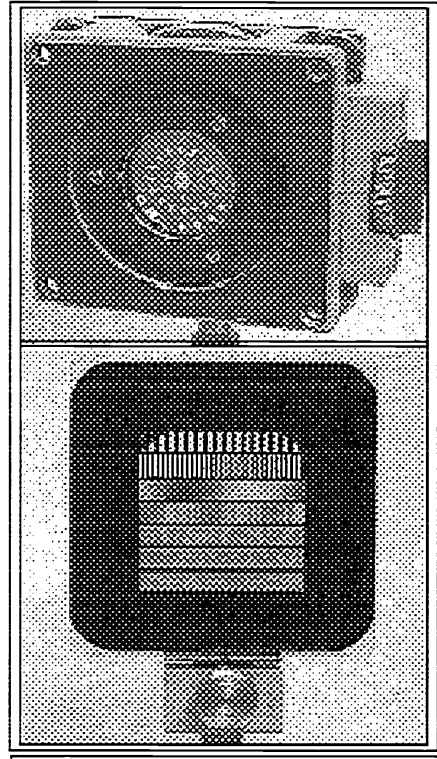

Fig.4 Manual modul with test-objects for laboratory experiments (top) and photolitograrhic gratings for lecture demonstrations.

\section{PHYSICAL TEST-OBJECTS}

There are several physics test-object: both the traditional optical elements (e.g. lenses, prisms, biprisms, mirrors, visual observation screens etc.) and the special optical objects to be made by a photolithography technology (e.g. differents slits, apertures, disks, one- and two-dimensional regular and irregular structures, objects with light reflection and light absorption dielectric films etc.). In addition, some cuvette collections with liquid solutions of different composition and radiation sources (e.g. spectral lamps, continuous spectrum imitator-lamps etc.) are made use. This object collection may be considerably extended in case of new optical materials application, for example, liquid crystals, microporous mediums, photosensitivity and structures of light radiation.

Examples of test-objects for labs and lecture demonstrations are shown in Fig.4 and 5. Because of uniform sizes one can use the same manual modules to support all test-objects. Diffraction and Interference Patterns from this objects are presented in Digital Image Files Collection, which formed by means of CCD-camera [3].

\section{CONCLUSIONS}

The samples of usage of the laboratory make possible to come to a conclusion about the good perspectives of OMEL devices for training in wave optics. The physical test objects, which were made by advantage technologies: submicron photolitography, film structures on isolator and semiconductor basis, flat reflectional optics, phototropic, microporous and liquid crystal matrixes and so on, have an interest, too. We think, such methods of education teach students to use PC, not only for calculation and vision, but as a control element in high-technology sistems. Another OMEL possibilites (Optoelectronics training, Optical Methods in Ecology, etc.) discuss in reports [1-2].

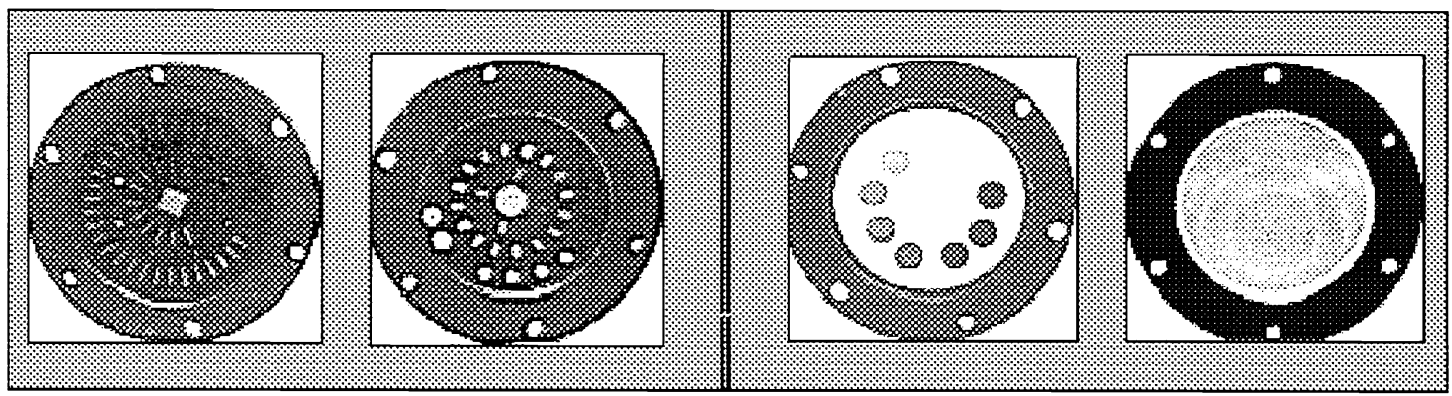

Fig.5 Examples of test-objects for diffraction and interference investigations: two amplitude photolitographic structures (left) with more than 100 different masks ( slits, holes, disks, rings, zone plates, 1D\&2D simple gratings, 1D Fourier-gratings, 2D periodic and random structures, etc.) and two film structures (right) with absorbtion and dielectric layers on the glass basis.

\section{REFERENCES}

1 Y.L.Kolesnikov, S.C.Stafeev and others, Training computerized laboratory for wave and quantum optics course, Proc. of the Conference "Education \& Training in Optics", p.192-196, Hungary, Pecs, 1993.

2. N.A.Jaryshev, S.C.Stafeev and others, Enhanced education in optics ..., Proc. of the Conference "Education \& Training in Optics", p.88-91, Hungary, Pecs, 1993.

3. S.A.Kozlov, S.C.Stafeev and others, Application of module education laboratory for enhanced training in Wave Optics, Proc. of the Conference "Education \& Training in Optics", p.88-91.

4.S.C.Stafeev, V.Y.Michnovetz and others, Windows Software for enhanced studying and testing knowlege in optics, same volume. 